\title{
Expressions of adenosine A2A receptors in coronary arteries and peripheral blood mononuclear cells are correlated in coronary artery disease patients
}

\author{
Vlad Gariboldi1, Donato Vairo1, Régis Guieu河
}

Correspondence information about the author Régis Guieu

$1, \mathbb{Q}$

Email the author Régis Guieu

, Marion Marlingue, Eléonore Ravis, David Lagier, Alissa Mari, Elsa Thery,

Frédéric Collart, Marine Gaudry, Laurent Bonello, Franck Paganelli, Jocelyne Condo, Nathalie Kipson, Emmanuel Fenouillet, Jean Ruf2, Giovanna Mottola2 PlumX Metrics

DOI: https://doi.org/10.1016/j.ijcard.2016.12.089 |

\section{CrossMark}

$\boxplus$ \#Article Info

- Abstract Full Text Images References

\section{Abstract}

\section{Background}

Altered coronary blood flow occurs in patients with coronary artery disease (CAD). Adenosine strongly impacts blood flow mostly via adenosine A2A receptor (A2AR) expressed in coronary tissues. As part of a systemic regulation of the adenosinergic system, we compared A2AR expression in situ, and on peripheral blood mononuclear cells (PBMC) in CAD patients.

\section{Methods and results}

Aortic and coronary tissues, and PBMC were sampled in 20 CAD patients undergoing coronary artery bypass surgery and consecutively included. Controls 
were PBMC obtained from 15 healthy subjects. Expression and activity of A2AR were studied by Western blotting and CAMP measurement, respectively. A2AR expression on PBMC was lower in patients than in controls ( $0.83 \pm 0.31$ vs $1.2 \pm$ 0.35 arbitrary units; $p<0.01$ ), and correlated with A2AR expression in coronary and aortic tissues (Pearson's r: 0.77 and 0.59, $p<0.01$, respectively). Basal and maximal CAMP productions following agonist stimulation of PBMC were significantly lower in patients than in controls ( $120 \pm 42$ vs $191 \pm 65$ and $360 \pm 113$ vs $560 \pm 215$ $\mathrm{pg} / 106$ cells, $p<0.05$, respectively). In CAD patients, the increase from basal to maximal cAMP production in PBMC and aortic tissues was similar $(+300 \%$ and $+246 \%$, respectively).

\section{Conclusion}

Expression of A2AR on PBMC correlated with those measured in coronary artery and aortic tissues in CAD patients, A2AR activity of PBMC matched that observed in aorta, and A2AR expression and activity in PBMC were found reduced as compared to controls. Measuring the expression level of A2AR 